\title{
Condensation-Fouling Interaction in Low-Temperature EGR-Coolers
}

\author{
Martin Reißig ${ }^{1, \mathrm{a}}$, Antje Hoppe ${ }^{2}$, Bert Buchholz ${ }^{1}$ and Egon Hassel ${ }^{2}$ \\ ${ }^{1}$ FVTR GmbH, 18059 Rostock, Germany \\ ${ }^{2}$ Rostock University, LTT, 18059 Rostock, Germany
}

\begin{abstract}
EGR cooling is a worthwhile technology capable of reducing NOx-emissions and increasing the efficiency of $\mathrm{CI}$ engines. Challenges arise when low-temperature cooling is applied with high fuel sulfur contents. The resulting sulfuric acid condenses in conjunction with the water of the exhaust gas and gives rise to corrosion of coolers and engine components. Additionally, fouling of the EGR cooler is exacerbated by the condensation of acidic components compromising EGR performance. In order to gain a better understanding of the underlying processes a combined experimental and model-based approach is presented. Tests of two different EGR-cooler concepts under various conditions showed a strong influence of the fuel sulfur content on fouling and condensation. The one-dimensional cooler model developed alongside these experiments consists of an activity coefficient model (NRTL) of the binary system water - sulfuric acid and a condensation model that allows for simulating the coupled condensation of both vapor components. Comparison of experimental fouling and simulated condensation results show good agreement in interpreting critical fouling phenomena that occur at temperatures in between the acid-water dew point and the dew point of pure water.
\end{abstract}

\section{Introduction}

In order to comply with stringent legislative regulations in regard to pollutant emissions and with increasing demand for energy efficient operation, engine manufactures employ a wide array of measures to meet these challenges. One such mean is the cooling of recirculated exhaust gas (EGR). EGR is widely used for reduction of $\mathrm{NO}_{\mathrm{x}}$-emissions of diesel engines by reducing maximum temperatures during combustion and promises to be an effective measure for enhancing the efficiency of these engines as well if thoroughly cooled. Challenges arise if low temperature EGR is operated on high sulfur fuel. Combustion then generates sulfur di- and trioxides, which in turn react with water in the exhaust gas forming sulfuric acid. Increased contents of sulfuric acid increase the dew point leading to condensation of water - sulfuric acid mixtures combined with other acidic components. Acidic condensate generated in the EGR cooler passing the corresponding downstream components results in problematic corrosion of metals and degradation of plastics. Huijbregts [1] reports three different corrosion failures involving acid condensation.

Furthermore, condensation gives rise to critical fouling in the EGR cooler itself, resulting in reduced efficiency or even failure of the EGR path (Figure 1).

Hoard [2] indicated that the build-up of deposits in EGR coolers causes a significant degradation in cooler

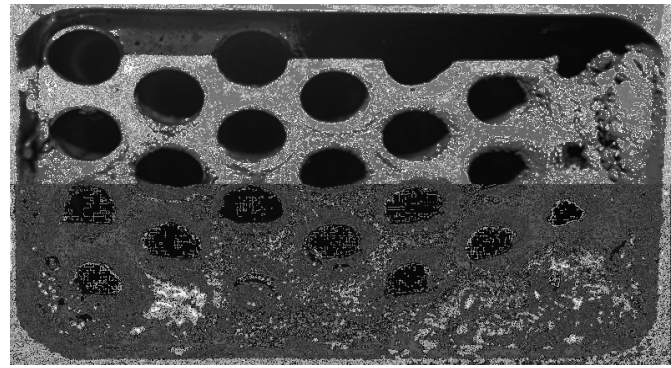

Figure 1: Critical cooler fouling of a shell\&tube EGR-cooler after stationary operation on high sulfur fuel

performance, often in the order of 20-30\%. Deposits act as a thermal insulator due to low thermal conductivity and high porosity [3]. As a main reason for the deposit build-up, low wall temperatures were stated causing thermophoretic soot deposition and condensation of unburned hydrocarbons (HC) and acidic components. Lower coolant temperatures were detected to increase the deposit mass extremely. Several acidic exhaust gas components are reported to condense potentially, such as sulfuric and nitric acid as well as organic acids (acetic, formic, butanoic acid). Among these, sulfuric acid turns out to be the most critical in regard to the dew point and the corrosivity of the exhaust gas $[4,5,6]$. There are several empirical correlations in the literature to determine the dew point of exhaust gases as a function of humidity and sulfuric acid content [7, 8, 9]. These

\footnotetext{
a Corresponding author: martin.reissig@fvtr.de
} 
formulas were parameterized with measured vapor liquid equilibrium (VLE) data of the system water - sulfuric acid. Other approaches are semi-empirical activity coefficient models $[10,11]$ and equations of state [12]. To predict the influence of condensate on particle deposition the amount of condensed vapor has to be modelled. Non-condensable components of the exhaust like nitrogen or carbon dioxide inhibit condensation by acting as a mass transfer resistance. Generally used film theory postulates an accumulation of inert gases near the phase interface building an additional resistance for heat and mass transfer. Wang [13] reported that the reduction in heat transfer due to inert gases is more significant at low pressures and low Reynolds numbers. For high Reynolds numbers Goldbrunner [14] indicated deviations from film theory: due to turbulences, a laminar boundary layer does not occur near the interface, consequently no accumulation of inert gases can be detected.

Ganzevles [15] ascertained that mixing and convection reduces the condensation heat resistance by a factor of four. Che [16] even reported that convective condensation heat transfer coefficient is 1.5-2 times higher than that of forced convection without condensation. Goldbrunner [14] also assumed that at high Reynolds numbers gaseous flow entrains droplets of the interface resulting in fog. Another fog building mechanism was reported by Land [5]: If the exhaust temperature near the interface falls below the dew point, droplet condensation in the boundary layer takes place causing fog formation. The formation of fog reduces the rate of acid deposition on the walls and increases with gas velocity. He indicated a maximum rate of acid deposition at surface temperatures $20-30 \mathrm{~K}$ below the dew point. A further reduction in surface temperature reduces this deposition due to fog formation. Similar discoveries were made by Cherkaoui [17] who divided condensation in two regimes: first pure film condensation, second film condensation coupled with fog formation near the interface. The temperature difference between bulk flow and the surfaces was detected as main criteria for condensation behavior. Based on an analogous approach McKinley [18] developed a model to estimate the amount water - sulfuric acid deposition of in both regimes. In order to calculate the dew point of water and sulfuric acid this modelling approach, however, uses empirical formulas of Abel [19]. These correlations base upon sparse date regarding the gas phase and therefore show discrepancies with recent measurement data. A more recent model developed by Jeong [20] assumes pure film condensation and estimates the rates of mass transfer for condensation of sulfuric acid and water individually.

Since in recent work condensation and fouling were investigated separately on the one hand and on the other hand cooling of EGR was moderate only, this contribution aims to shed light on the condensationfouling interaction with low-temperature EGR-cooling. In addition to experimental work with two cooler concepts, a one-dimensional condensation model taking the VLE of the binary system sulfuric acid - water into account is applied to achieve this.

\section{Experimental set-up}

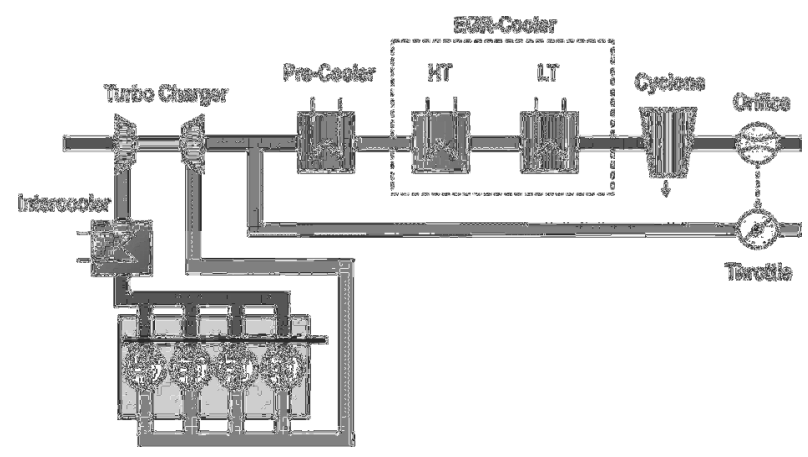

Figure 2: EGR-cooler test bench

A component test bench was employed as depicted in Figure 2. The exhaust gas was generated by a 2,2 1 Common Rail Diesel engine, temperature conditioned by a pre-cooler and finally led through a high- and a low-temperature cooler. All three coolant circuits as well as the exhaust mass flow were controlled delivering steady boundary conditions. The engine was operated on regular (5 ppm S) DIN EN 590 Diesel fuel and on 1000 ppm S Diesel fuel.

Temperature and pressure sensors were installed upstream and downstream of each EGR cooler. Additionally temperature sensors were applied between each cooling package. Condensate was extracted using a cyclone demister. A by-pass allowed for varying the mass flow through the EGR coolers without changing the engine operation.

The cooling concept consists of a high temperature cooler (HT) and a low temperature cooler (LT). This design is typical for low temperature EGR-cooling systems as it allows the HT cooler to be operated with engine coolant and the LT cooler with a separate cooling circuit. As condensation does not take place in HT cooling and fouling of the HT coolers was uncritical, the LT coolers are part of the investigation only. Two EGR-cooler geometry-concepts were investigated: finned-tube and shell\&tube heat exchangers. Figure 3 and Figure 4 show the LT components of both geometry concepts. Each cooler consists of a number of cooling packages, 15 with the finned-tube cooler and 6 with the shell\&tube cooler.

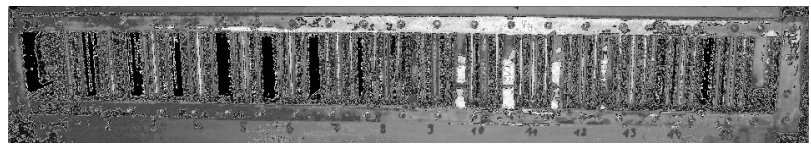

Figure 3: Finned-tube EGR-cooler

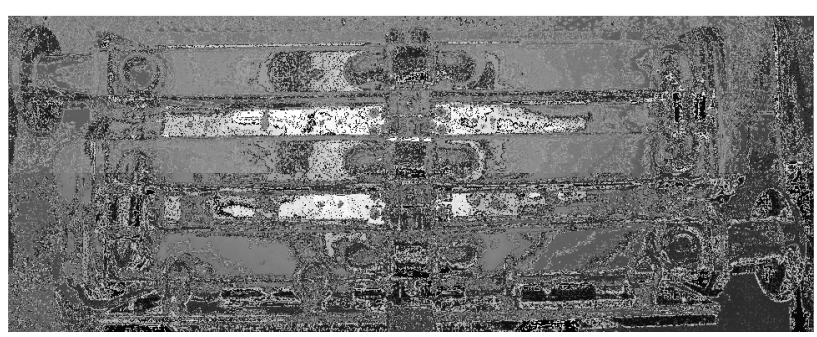

Figure 4: Shell\&tube EGR-cooler 
Two different kinds of experiments were conducted: Long duration runs with $15 \mathrm{~h}$ of stationary operation in order to investigate the fouling behaviour; brief runs for model validation of not more than one hour to ensure stationary operation on the one hand but marginal fouling effects on the other hand. Table 1 shows the corresponding boundary conditions.

Table 1: Experimental boundary conditions

\begin{tabular}{|c|c|c|c|c|}
\hline Experiment & I & II & III & IV \\
\hline Cooler & $\begin{array}{c}\text { Finned- } \\
\text { tube }\end{array}$ & $\begin{array}{c}\text { Finned- } \\
\text { tube }\end{array}$ & $\begin{array}{c}\text { Shell\& } \\
\text { tube }\end{array}$ & $\begin{array}{c}\text { Shell\& } \\
\text { tube }\end{array}$ \\
\hline $\begin{array}{c}\text { Exhaust gas } \\
\text { mass flow }\end{array}$ & $\begin{array}{c}300 \\
\mathrm{~kg} / \mathrm{h}\end{array}$ & $\begin{array}{c}300 \\
\mathrm{~kg} / \mathrm{h}\end{array}$ & $\begin{array}{c}300 \\
\mathrm{~kg} / \mathrm{h}\end{array}$ & $\begin{array}{c}300 \\
\mathrm{~kg} / \mathrm{h}\end{array}$ \\
\hline $\begin{array}{c}\text { Gas inlet } \\
\text { temperature }\end{array}$ & $140{ }^{\circ} \mathrm{C}$ & $140{ }^{\circ} \mathrm{C}$ & $250{ }^{\circ} \mathrm{C}$ & $275^{\circ} \mathrm{C}$ \\
\hline $\begin{array}{c}\text { Coolant } \\
\text { temperature }\end{array}$ & $30{ }^{\circ} \mathrm{C}$ & $30{ }^{\circ} \mathrm{C}$ & $20{ }^{\circ} \mathrm{C}$ & $80^{\circ} \mathrm{C}$ \\
\hline $\begin{array}{c}\text { Filter Smoke } \\
\text { Number }\end{array}$ & 1,1 & 1,1 & 1,1 & 1,1 \\
\hline Fuel sulfur & 1000 & $\begin{array}{c}5 \\
\mathrm{ppm}\end{array}$ & $\begin{array}{c}1000 \\
\mathrm{ppm}\end{array}$ & $\begin{array}{c}1000 \\
\mathrm{ppm}\end{array}$ \\
\hline Duration & $15 \mathrm{~h}$ & $15 \mathrm{~h}$ & $<1 \mathrm{~h}$ & $<1 \mathrm{~h}$ \\
\hline
\end{tabular}

\section{Condensation model}

The modelling approach used for supporting the findings of the experiments and for studying the effects of several variables is based upon a 1D thermodynamic model of the heat exchanger. The model includes mass, energy and momentum balances with heat transfer extended by a condensation model that is presented in the following. It consists of a VLE-model capable of describing the phase equilibrium of the binary system water - sulfuric acid and a mass transfer model which estimates the condensation rate.

In order to limit model complexity necessary assumptions are:

- The cooler is assumed to work in steady-state.

- All balances are solved one-dimensionally by discretising every cooling package in two control volumes.

- Exhaust gas consists of nitrogen, oxygen, water, carbon dioxide, sulphur dioxide and sulfuric acid. The fraction of the components is estimated using formulas of McKinley [18]. An ideal gas approach is used.

- Fouling is not part of the condensation model. Therefore the cooler is assumed to be void of solid deposits.

- Condensable exhaust components are limited to water and sulfuric acid; other components are considered to be inert.

- Condensation has no effect on the exhaust flow and on the heat transfer coefficient; specific character of two-phase flow is neglected. Only enthalpy of condensation is taken into account.

- Condensation takes place only as film condensation on the tube walls (no fog). There are no chemical reactions in the condensate. Once condensed, the fluid is assumed to stay in the liquid phase.

- At the phase interface thermodynamic equilibrium is assumed.

\subsection{Vapor-liquid equilibrium}

To calculate the saturation temperature of the water sulfuric acid mixture an activity coefficient model is used. For non-ideal VLE the fugacity of the vapor $f_{i}^{V}$ is equal to the fugacity of the liquid phase $f_{i}^{L}$ for each species $i$

$$
\begin{gathered}
f_{i}^{V}=f_{i}^{L} \\
p \cdot y_{i} \cdot \varphi_{i}^{V}=x_{i} \cdot \gamma_{i} \cdot f_{i}^{+}
\end{gathered}
$$

As standard fugacity $f_{i}^{+}$the fugacity of the pure component $i$ at saturation state $p_{i}^{0}$ is selected. Assuming an ideal vapor phase $\left(\varphi_{i}^{V}=1\right)$ eq. (2) simplifies to

$$
p_{i}=p \cdot y_{i}=x_{i} \cdot \gamma_{i} \cdot p_{i}^{0}
$$

The activity coefficients $\gamma_{i}$ are determined using the NRTL approach [21] and can be calculated as follows

$$
\ln \gamma_{i}=\frac{\sum_{j} \tau_{j i} G_{j i} x_{j}}{\sum_{k} G_{k i} x_{k}}+\sum_{j} \frac{x_{j} G_{i j}}{\sum_{k} G_{k j} x_{k}}\left(\tau_{i j}-\frac{\sum_{n} x_{n} \tau_{n j} G_{n j}}{\sum_{k} G_{k j} x_{k}}\right) \text {. }
$$

The parameters $\tau_{i j}$ and $G_{i j}$ are temperature-dependent and can be calculated with Eq. (5) - (7). [22]

$$
\begin{gathered}
\tau_{i j}=A_{i j}+\frac{B_{i j}}{T}+E_{i j} \cdot \ln T+F_{i j} \cdot T \\
\alpha_{i j}=C_{i j}+D_{i j} \cdot(T-273.15 \mathrm{~K}) \\
G_{i j}=\exp \left(-\alpha_{i j} \cdot \tau_{i j}\right)
\end{gathered}
$$

The coefficients $A$ to $F$ were fitted to measurement data. In order to increase the accuracy of the model at relevant concentrations sulfuric acid vapor mole fractions greater than 0.5 were neglected during the optimization process, indicated by a dashed line in Figure 5 .

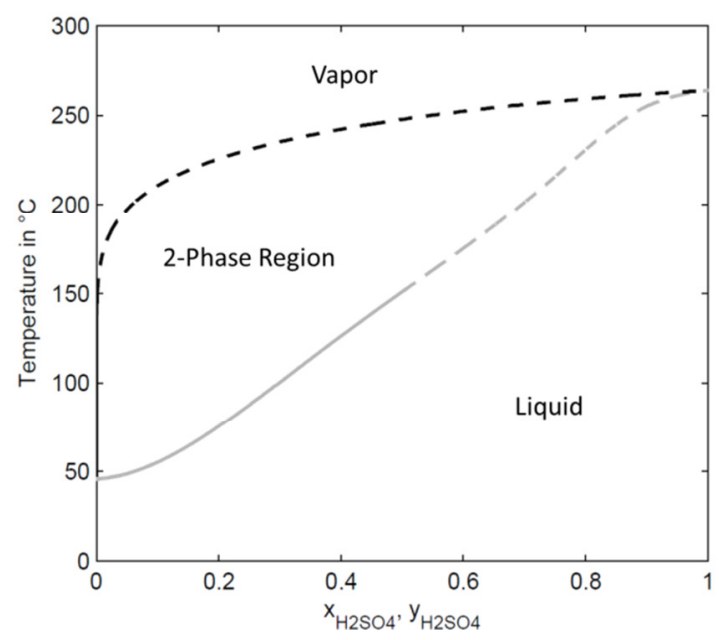

Figure 5: Phase diagram for the binary system water sulfuric acid at 0.1 bar 


\subsection{Condensation rate}

Condensation of the water - sulfuric acid vapor occurs in the presence of the non-condensable exhaust gas. Assuming film condensation on the heat exchanger walls, the temperature at the condensate surface is equal to the saturation temperature of the vapor mixture. Noncondensable gases impede the condensation process acting as a mass transfer resistance. Thus, the rate of phase change is considerably higher than the diffusion rate. Consequently, non-condensable gases accumulate at the condensate surface resulting in a concentration difference between the vapor at the interface $c_{v, i}$ and in the bulk flow $c_{v, b}$ [23]. This gradient and the value of the mass transfer coefficient $\beta$ determine the dimension of the molar flux to the interface $A$

$$
\dot{n}_{v}=\beta \cdot A \cdot\left(c_{v, b}-c_{v, i}\right)
$$

The mass transfer coefficient $\beta$ results from the ChiltonColburn-Analogy [24], [25]

$$
\beta=\frac{\alpha_{g}}{\varrho_{g} \cdot c_{p, g} \cdot L e_{\text {vap-gas }}^{2 / 3}}
$$

where $\alpha_{g}$ is the heat transfer coefficient, $\varrho_{g}$ the density and $c_{p, g}$ the specific heat of the exhaust. The required Lewis number is estimated with the following approach using the thermal diffusivity of air $a_{\text {air }}$ and the binary diffusion coefficient $D_{\text {vapour-air }}$ of vapor in air [26]

$$
L e_{\text {vapour-gas }}=\frac{a_{\text {air }}}{D_{\text {vapour-air }}} .
$$

The diffusion coefficients of water and sulfuric acid are temperature dependent and are calculated with correlations of Pla Perujo [27].

Using the logarithmic mean mole fraction of the inert gas

$$
y_{g, l m}=\frac{y_{g, i}-y_{g, b}}{\ln \left(\frac{y_{g, i}}{y_{g, b}}\right)}
$$

the resulting mass flux of the vapor is

$$
\dot{m}_{v}=\frac{\alpha_{g} M_{v}}{c_{p, g} M_{g} y_{g, l m} L e_{v a p-g a s}^{2 / 3}} A\left(y_{v, b}-y_{v, i}\right) .
$$

To determine the condensation ratios of water and sulfuric acid two different approaches were used.

\subsubsection{Non-interacting condensation}

As a reference, a model by Jeong [20, 28, 29] was implemented. This model describes a separate, noninteracting condensation of water and sulfuric acid. For both vapor components - water and sulfuric acid, a separate mass flux depending on the individual saturation condition is calculated

$$
\begin{gathered}
\dot{m}_{H 2 S O 4}=\frac{\alpha_{g} M_{H 2 S O 4} A\left(y_{H 2 S O 4, b}-y_{H 2 S O 4, i}\right)}{c_{p, g} M_{g} y_{g, l m} L e_{H 2 S O 4-a i r}^{2 / 3}} \\
\dot{m}_{H 2 O}=\frac{\alpha_{g} M_{H 2 O} A\left(y_{H 2 O, b}-y_{H 2 O, i}\right)}{c_{p, g} M_{g} y_{g, l m} L e_{H 2 O-a i r}^{2 / 3}}
\end{gathered}
$$

The vapor mole fraction at the interface $y_{v, i}$ is determined using empirical relations for the partial pressure at saturation $p_{v, i}$ and an ideal gas approach

$$
y_{v, i}=\frac{p_{v, i}}{p_{t o t}}
$$

For sulfuric acid a correlation of Verhoff and Banchero [8] is used; the partial pressure of water is calculated using the Antoine equation.

The deficit of this model is the de-coupling of the two condensate fluxes: For wall temperatures below the saturation point of sulfuric acid but above the saturation point of water the condensation of pure sulfuric acid is stipulated. However it is well known from literature (e.g. $[1,7,30])$ that vapor mixtures of water and sulfuric acid condense as a mixture even in the presence of inert gases. To overcome this shortfall a condensation model based upon an activity coefficient model (NRTL) was developed. It allows for the simulation of an interacting condensation of water and sulfuric acid in the exhaust gas.

\subsubsection{Interacting condensation}

The interacting condensation model assumes that the equilibrium at the interface of condensate and exhaust gas forms in the same way as it would without inert gases; that means by a local change in binary composition. Figure 6 illustrates the process: For a vapor mixture with the composition $y_{1, b}$ flowing over a wall of the temperature $T_{W}$, and $T_{W} \leq T_{\text {sat }}$, condensation occurs. Assuming partial condensation, that means wall temperature is higher than boiling temperature $T_{\text {boil }}$, equilibrium conditions at the interface is achieved decreasing the vapor of component 1 to $y_{1, i}$. The corresponding mole fraction of component 1 in the condensate is $x_{1, V L E}$. If, on the other hand, wall temperatures $T_{\text {tot }}$ fall below the boiling temperature of the mixture $T_{\text {boil }}$ total condensation occurs [31]. As a consequence, the composition of the condensate is equal to the vapor bulk composition $\left(x_{1, V L E}=y_{1, b}\right)$. The vapor mole fraction at the interface $y_{1, t o t}$ corresponds to the boiling temperature of the mixture. According to the phase diagram of water and sulfuric acid shown in Figure 5 for both condensation phenomena the VLE at the condensate interface will be reached by a decrease of sulfuric acid vapor and an analogous increase of relative water vapor content. However, the partial pressure of the binary vapor mixture in the exhaust is assumed to be constant 


$$
p_{\mathrm{H} 2 \mathrm{O}, \mathrm{b}}+p_{\mathrm{H} 2 \mathrm{SO}, \mathrm{b}}=p_{\mathrm{H} 2 \mathrm{O}, \mathrm{i}}+p_{\mathrm{H} 2 \mathrm{SO}, \mathrm{i},}
$$

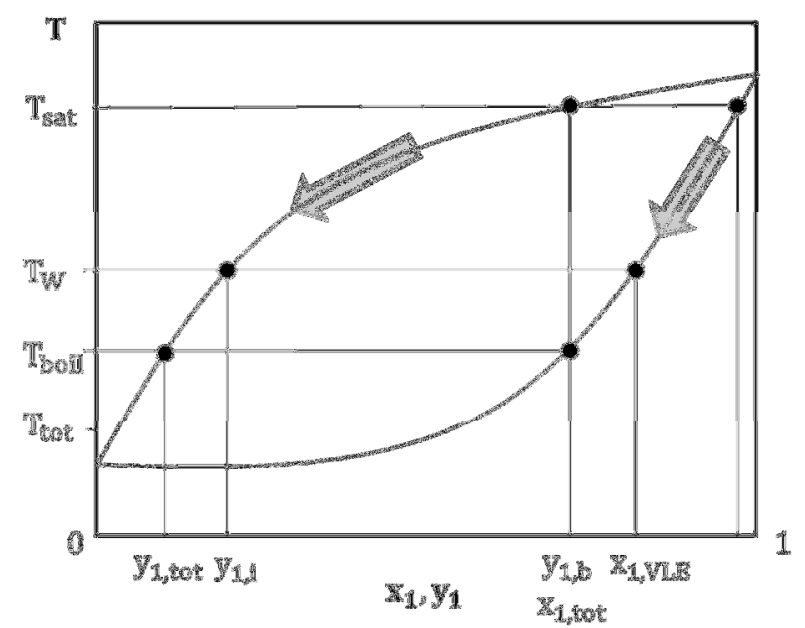

Figure 6: Binary vapor-liquid equilibrium

Consequently there will be a strong concentration gradient for sulfuric acid between the bulk and the interface. This leads to the conclusion that the condensation rate is predominantly limited by the diffusional transport of sulfuric acid vapor molecules to the phase interface. Due to this, condensation rates of water and sulfuric acid will be calculated as follows: The mass flux of sulfuric acid condensate is determined using eq. (13) but calculating the vapor mole fraction of sulfuric acid at the interface using the NRTL approach. To estimate the mass flux of simultaneously condensing water the mole fraction of water in the liquid which corresponds to $y_{H 2 S O 4, i}$ and the wall temperature is determined iteratively using the NRTL model. With the information about the molar fraction of water in the condensate and the mass flux of sulfuric acid the condensation rate of water can be estimated by

$$
\dot{m}_{\mathrm{H} 2 \mathrm{O}}=\frac{\dot{m}_{\mathrm{H} 2 \mathrm{SO} 4}}{M_{\mathrm{H} 2 \mathrm{SO} 4}} \cdot \frac{x_{H 2 O}}{1-x_{H 2 O}} \cdot M_{H 2 O}
$$

In contrast to the non-interacting condensation model of Jeong just one single saturation point of the mixture is estimated. In consequence the condensate comprises both vapors in differing compositions depending on exhaust composition and wall temperature.

\subsection{Enthalpy of condensation}

Apart from mass fluxes, condensation leads to an increase in heat load on the cooler in the form of condensation enthalpy

$$
\dot{Q}=\alpha_{g} \cdot A_{i} \cdot\left(T_{b}-T_{i}\right)+\Delta H_{v} \cdot \dot{n}_{v}
$$

For the condensation of water and sulfuric acid enthalpy flow of condensation can be expressed as

$$
\Delta H_{v} \dot{n}_{v}=\Delta H_{v, H 2 O} \dot{n}_{H 2 O}+\Delta H_{v, H 2 S O 4} \dot{n}_{H 2 S O 4}
$$

The molar enthalpy of condensation of water is estimated using the DIPPR 106 equation [32]

$$
\Delta H_{v, H 2 O}=A \cdot\left(1-T_{r}\right)^{B+C \cdot T_{r}+D \cdot T_{r}^{2}+E \cdot T_{r}^{3}}
$$

with the reduced temperature $T_{r}=T / T_{c}$. The molar enthalpy of condensation of sulfuric acid is assumed to be constant $\Delta H_{v, H 2 S O 4}=78.87 \mathrm{~kJ} / \mathrm{mol}$ [33].

\section{Results and Discussion}

\subsection{Experimental Results}

The experimental variation of fuel sulfur level was conducted with the finned tube cooler. The resulting pressure loss coefficient shows higher values for operation under high sulfur levels. Time averaged gradients are $0,103 \mathrm{~h}^{-1}$ with high sulfur vs. $0,055 \mathrm{~h}^{-1}$ with low sulfur fuel. This observation of increased pressure loss due to fouling is verified by fouling pictures which are depicted in Figure 7. Exemplary cooling packages are shown in the upper part for the experiment with 1000 ppm sulfur. Clearly visible is an increase in the particle
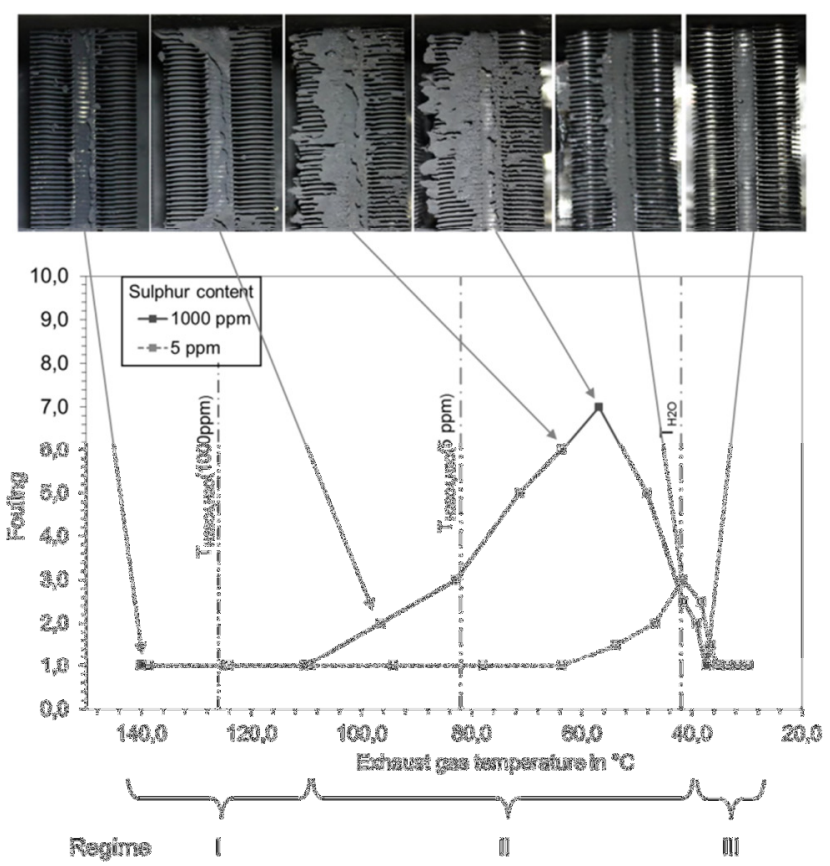

Figure 7: Qualitative fouling along the finned-tube cooler length for a fuel sulfur variation (exp. no. I \& II)

deposits along the cooler length. After a maximum at about the mid of the cooler, fouling decreases due to rinsing by high condensate mass flows. This fouling is interpreted into a fouling number with 0 for a clean cooling package and 10 for a completely blocked one. The diagram below shows the result for both experiments - 5 and 1000 ppm S - as a function of cooling package and bulk temperature respectively. This type of experiments shows that for bulk temperatures well above the sulfuric acid - water dew point uncritical dry fouling results. This regime is well known from more conservative EGR-cooler concepts and is uncritical for cooler operation as deposits and pressure loss converge even during stationary engine operation (foulingregime I). With further cooling of the exhaust gas a more critical regime occurs with serious deposit build-up (fouling-regime II). It is caused by small amounts of 
condensed vapor that form sticky deposits in conjunction with the exhaust particles attracting more particles. Condensate increases cohesion of the deposits in a form such that abrasion cannot occur as it does in the dry fouling-regime. This regime did not converge during observed operations durations and proves to be critical to EGR cooler operation. This regime is loosely correlated to the sulfuric acid - water dew point, as can be seen in Figure 7 where the onset is located about $20 \mathrm{~K}$ below the calculated dew-point. If the exhaust gas reaches lower temperatures than the water dew point, rinsing of the cooler surfaces can be observed. In this case condensate mass flow cumulates along the cooler length in such an amount that particles cannot deposit which leads to nearly clean surfaces (fouling-regime III). Although fouling is not an issue with this regime, two drawbacks have to be taken into account, when operating under low temperature conditions: High condensation rates which have to be dealt with and the corresponding condensation enthalpy flow which increases the cooling demand.

Additionally to these observations, that are common to both fuel sulfur levels, significant differences occur in the form of higher fouling amplitudes with high sulfur levels as well as an onset of critical fouling that is shifted to higher temperatures compared to the low sulfur level. According to these findings the amount of sulfuric acid plays a major role in EGR cooler fouling. A hypothesis for these phenomena is that sulfuric acid and water condense on the surfaces of the cooler in such amounts that a sticky environment develops. Particles that are abundant in the diesel engine exhaust accumulate on this surface forming deposits that are more robust to abrasion than deposits that form under dry conditions. This leads to a non-convergent pressure loss behavior of the EGRcooler with serious consequences for engine operation.

\subsection{Simulation results}

\subsubsection{Condensation rate}

Simulated condensation rates of water and sulfuric acid are shown in Figure 8. For experiment no. III both models predict similar condensate fluxes, especially for sulfuric acid. The maximum condensation rate is estimated in the first cooling package due to maximum vapor partial pressure gradient between the bulk flow and the interface. The following cooling packages exhibit lower condensate rates. The results of experiment no. IV demonstrate the difference between the two condensation models: Due to wall temperatures above the saturation point of pure water but below the saturation temperature of sulfuric acid the non-interacting model predicts a condensate flux of pure sulfuric acid whereas the interacting model always considers the corresponding water condensation due to mixture behavior. Table 2 compares the integral condensate rates of the experimental set-up and the two condensation models. For both models the condensation fluxes for experiment no. III are over-predicted compared to the measured data. Taking the separation efficiency of the cyclone into account with values between 80 and $90 \%$ the simulated

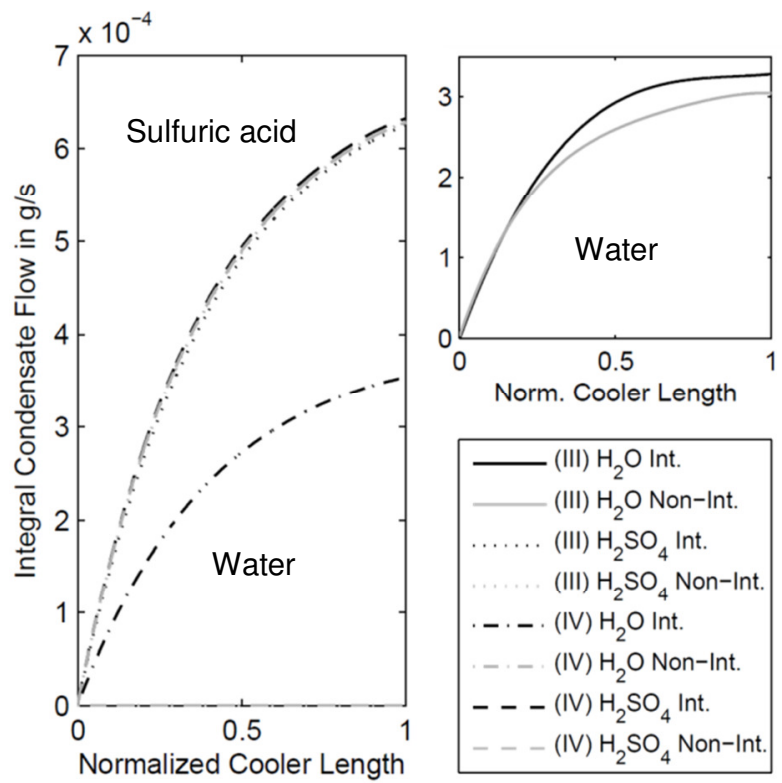

Figure 8: Simulated condensation rates of sulfuric acid and water for the investigated condensation models

results of both models can be regarded as satisfying. For experiment no. IV there is a large discrepancy between simulation and measurement.

A likely explanation for this effect is the lack of a thermal insulation of the cyclone. Consequently wall temperatures in the cyclone could have fallen below the saturation temperature of the exhaust gases and condensation could have taken place. It is supposed that nearly the complete measured condensate was not built up in the cooler but in the cyclone instead. Optical analysis of the cooler's inside after the experiment confirms this assumption.

Table 2: Measured and simulated integral condensation rates

\begin{tabular}{|c|c|c|c|}
\hline Exp. & Measurement & $\begin{array}{c}\text { Non- } \\
\text { interacting }\end{array}$ & Interacting \\
\hline III & $9.02 \mathrm{~kg} / \mathrm{h}$ & $11.00 \mathrm{~kg} / \mathrm{h}$ & $11.78 \mathrm{~kg} / \mathrm{h}$ \\
\hline IV & $107.8 \mathrm{~g} / \mathrm{h}$ & $2.262 \mathrm{~g} / \mathrm{h}$ & $3.553 \mathrm{~g} / \mathrm{h}$ \\
\hline
\end{tabular}

For a better understanding of condensation processes in the cooler Figure 9 shows the calculated integral condensate rate of both models as a function of coolant temperature with a constant exhaust inlet temperature of $265^{\circ} \mathrm{C}$. Generally the interacting model predicts higher condensate rates than the non-interacting by Jeong. However, both models consistently predict a sharp bend at temperatures of about $42.5^{\circ} \mathrm{C}$. For higher coolant inlet temperatures simulated wall temperatures stay above the dew point of pure water along the cooler length. Consequently the non-interacting model simulates no water condensation, so condensate rate decreases considerably.

Due to the low sulfuric acid concentration of the exhaust the dew point of pure water nearly fits in with the boiling point of the water-sulfuric acid mixture. Hence, for coolant inlet temperatures above $42.5^{\circ} \mathrm{C}$ no total condensation occurs along the cooler length but partial 

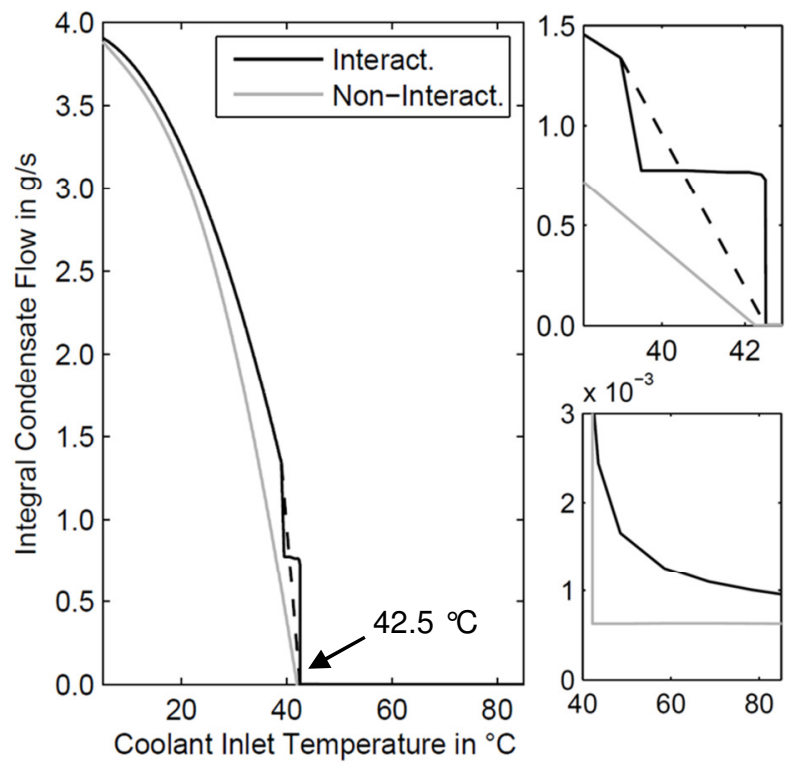

Figure 9 :Simulated integral condensate rate of the shell\&tube EGR-cooler for a coolant temperature variation

condensation only resulting in a strong decrease of condensate rate. However, sulfuric acid and water are assumed to condensate always coupled. Thus the simulated condensate rate of the interacting model exceeds the rate based on the non-interacting approach also for high coolant temperatures. This of importance for understanding the fouling behavior in the temperature region of fouling regime II. Small but significant levels of condensation occur, leading to the aforementioned sticky deposits.

Furthermore the interacting model simulates a nearly constant condensate rate between coolant inlet temperatures of $39.5^{\circ} \mathrm{C}$ and $42.5^{\circ} \mathrm{C}$. In this range maximum condensate rate shifts away from cooler inlet to rear sectors. Calculated condensate rates are supposed to be a consequence of the coarse discretisation. The dashed line shows a more realistic curve shape which should be realizable by a finer spatial discretisation.

\subsubsection{Condensate composition}

Table 3 lists measured and simulated sulfuric acid mole concentrations in the condensate. As expected, sulfuric acid concentration increases with higher coolant temperatures. For experiment no. III simulation results of both models fit well with measured data.

For experiment no. IV results differ significantly. The output of the non-interacting model follows from the decoupled estimation of condensate rates. In this case condensation of pure sulfuric acid is simulated, so the failure is model-internal. The large discrepancy between measurement and interacting model confirms the uncertainty of the measured condensate rates by the cyclone: Based on the phase diagram (Figure 5) at wall temperatures of about $80{ }^{\circ} \mathrm{C}$ the molar sulfuric acid content in the condensate is at least $20 \%$. The measured sulfuric acid content is significantly smaller and is an indication for an additional condensation in the cyclone.
Table 3: Measured and simulated condensate sulfuric acid mole fractions

\begin{tabular}{|c|c|c|c|}
\hline Exp. & Measurement & $\begin{array}{c}\text { Non- } \\
\text { interacting }\end{array}$ & Interacting \\
\hline III & $36 \mathrm{ppm}$ & $38 \mathrm{ppm}$ & $35 \mathrm{ppm}$ \\
\hline IV & $511 \mathrm{ppm}$ & $100 \%$ & $25 \%$ \\
\hline
\end{tabular}

\subsubsection{Exhaust gas temperatures}

Figure 10 shows the simulated exhaust gas temperatures in comparison to measurement data.

As expected, estimated as well as measured temperatures decrease along the cooler with diminishing gradient. Due to a high coolant mass flow wall temperatures increase marginally only. Thus the temperature gradient between exhaust bulk and cooler wall decreases along the cooler resulting in a reduced heat flow.

Both models predict nearly equal exhaust temperatures. Main deviations can be traced for experiment no. III due larger absolute differences in estimated condensation rates causing differences in enthalpy of condensation rates.

For low condensation rates as stated for experiment no. IV simulated and measured temperatures agree well. In contrast, measured temperatures for experiment no. III differ significantly from simulated results. Condensation rates are suspected as the cause. Contrary to literature [20] condensation effects on the heat transfer do not seem to be marginal - at least for high condensation rates. It is assumed that due to high exhaust velocities and condensate flows there is no all-over condensate film at the tube walls which would act as an additional heat resistance. It is rather possible that built-up condensate is carried away from the wall by the exhaust flow resulting in fog flow. Studies of common two-phase-flows [34] confirm this assumption. Condensate droplets in the flow are reheated and evaporated. Hence condensation seems to improve the heat transfer significantly. Similar conclusions were drawn by Che [16].

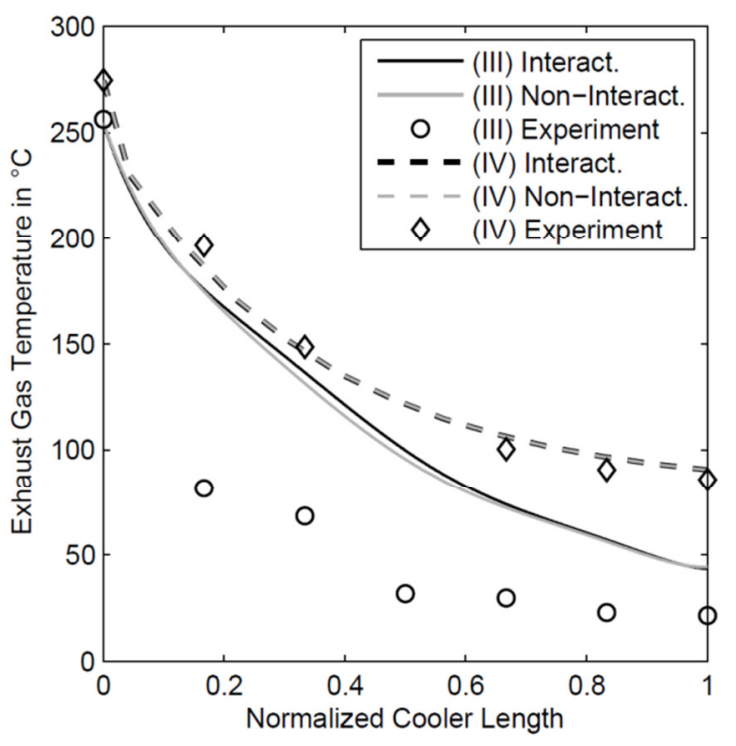

Figure 10: Measured and simulated exhaust gas temperatures 


\section{Conclusion}

- Low-temperature EGR-cooling results in three successive fouling regimes of the cooler:

I. Dry, uncritical fouling at temperatures well above the acid-water vapor dew-point.

II. Sticky, critical fouling between the acidwater vapor dew-point and the dew-point of pure water. Simulation results support the theory of small condensation rates as a cause for this sticky condition at the surfaces.

III. Rinsing of cooler surfaces with high condensate rates at low temperatures below the water dew-point.

- High contents of sulfur in the fuel causes increased fouling with an increase in the critical temperature range that is fouling regime II and higher deposit masses.

- High condensate mass flows are to be handled with low temperature cooling.

- High acidity of the condensate implies necessary measures to guarantee a sufficient life time of engine components.

- High condensate flows affect/enhance heat transfer in the EGR cooler significantly.

- Condensate rate increases with decreasing coolant/wall temperature respectively increasing temperature gradient between bulk flow and cooler wall. Sulfur content of the condensate decreases with decreasing coolant temperature.

- Rate of condensation depends strongly on wall temperature. If the wall temperature does not fall below boiling temperature of the water-sulfuric acid mixture along the whole cooler length condensate rate reduces considerably compared to lower wall temperatures.

- The interacting condensation model enables simulation of coupled condensation of water and sulfuric acid, even for higher wall temperatures (above saturation temperature of pure water).

\section{References}

1. W. M. M. Huijbregts, R. G. I. Leferink, Anti-Cor. Meth. Mat. 51, 3, 173-188 (2004)

2. J. Hoard, M. Abarham, D. Styles, J. M. Giuliano, C. S. Sluder, J. M. E. Storey, SAE Tech. Paper 200801-2475

3. J. Lance, C. S. Sluder, H. Wang, J. M. E. Storey, SAE Tech. Paper 2009-01-1461

4. J. W. Girard, L. D. Gratz, J. H. Johnson, S. T. Bagley, D. G. Leddy, SAE Tech. Paper 1999-013566

5. T. Land, Journ. Inst. Fuel, 68, 68-75 (1977)
6. A. M. Kreso, J. H. Johnson, L. D. Gratz, S. T. Bagley, D. G. Leddy, SAE Tech. Paper 981423

7. R. Haase, H.-W. Borgmann, Mit. d. VGB, 76, 16-19 (1962)

8. F. H. Verhoff, J. T. Banchero, Chem. Eng. Proc. 70, 8, 71-72 (1974)

9. B. ZareNezhad, Oil \& Gas Journ. 35, 107, 60-63 (2009)

10. F. L. P. Pessoa, P. Rasmussen, A. Fredenslund, Lat. Am. Appl. Res., 22, 195-206 (1992)

11. H. Que, Y. Song, C. Chen, J. Chem. Eng. Data, 56, 963-977 (2011)

12. J. Helmig, Beitrag zur Korrelation von Phasengleichgewichtsdaten (1983)

13. C. Y. Wang, C.-J. Tu, Int. J. Heat Mass Transfer, 31, 2339-2345 (1988)

14. M. Goldbrunner, Lokale Phänomene bei der Kondensation von Dampf in Anwesenheit eines nichtkondensierbaren Gases (2003)

15. F. L. A. Ganzevles, C. W. M. van der Geld, Int. J. Heat Mass Transfer, 45, 3233-3243 (2002)

16. D. Che, Y. Da, Z. Zhuang, Heat Mass Transfer 3, 41, 250-256 (2005)

17. H. Cherkaouil, W. Maref, J. Chandellier, P. Crausse, H. Boisson, Y. Benjelloun, Rev. Gén. Therm., 36, 771-781 (1997)

18. T. L. McKinley, SAE Tech. Paper 970636, 207-218 (1997)

19. E. Abel, J. Phys. Chem., 101, 598-606 (1979)

20. K. Jeong, E. K. Levy, IJHMT, 55, 8010-8019 (2012)

21. J. M. Prausnitz, H. Renon, AIChE 14, 1, 135-144 (1968)

22. Aspen Technology Inc., Aspen Physical Property Systems: Physical Property Models (2010)

23. D. G. Kroger, W. M. Rohsenow, IJHMT 11, 1, 15-26 (1968)

24. T. H. Chilton, A. P. Colburn, Ind. Eng. Chem. 26, 11, 1183-1187 (1934)

25. A. P. Colburn, AIChE, 29, 174-210 (1933)

26. M. Osakabe, Proc. of the ASME Heat Transfer Division, 2, 43-50 (1999)

27. M. Pla Perujo, Condensation of water vapor and acid mixtures from exhaust gases (2004)

28. K. Jeong, Condensation of Water Vapor and Sulfuric Acid in Boiler Flue Gas (2009)

29. K. Jeong, M. J. Kessen, H. Bilirgen, E. K. Levy, IJHMT, 53, 2361-2368 (2010)

30. J. Rolker, VGB KWT 53, 5, 333-339 (1973)

31. K. Asano, Mass Transfer: From Fundamentals to Modern Industrial Applications (Wiley-VCH, Weinheim, 2006)

32. Dortmund Data Bank Software \& Separation Technology, Pure Component Equations : Fitting of Pure Component Equations (2009)

33. K. E. Grant, An Aerosol Condensation Model for Sulfur Trioxide (2008)

34. M. Kraume, Transportvorgänge in der Verfahrenstechnik: Grundlagen und apparative Umsetzungen (Springer Vieweg, Berlin, 2012) 